\title{
INTERCEPTAÇÃO DA RADIAÇÃO FOTOSSINTETICAMENTE ATIVA E RENDIMENTO DE GRÃOS DO MILHO ADENSADO ${ }^{1}$
}

\author{
ROBÉLIO LEANDRO MARCHÃO ${ }^{2}$, EDWARD MADUREIRA BRASIL ${ }^{3}$ e PAULO ALCANFOR \\ XIMENES ${ }^{3}$
}

\begin{abstract}
${ }^{1}$ Parte da dissertação de mestrado do primeiro autor, apresentada à Universidade Federal de Goiás.
${ }^{2}$ Eng $^{\circ}$ Agrônomo, Doutorando em Agronomia - Programa de Pós-graduação em Agronomia. Escola de Agronomia e Engenharia de Alimentos da Universidade Federal de Goiás. CP 131 - CEP 74001-970. Goiânia - Goiás. E-mail: robelio@cnpaf.embrapa.br Bolsista CNPq.

${ }^{3}$ Eng $^{\circ}$ Agrônomo, Prof ${ }^{o}$ Adjunto - Universidade Federal de Goiás, Escola de Agronomia e Engenharia de Alimentos, Caixa Postal 131,CEP 74001-970 Goiânia, GO.E-mail: ebrasil@ reitoria.ufg.br, ximenes@ prograd.ufg.br
\end{abstract}

Revista Brasileira de Milho e Sorgo, v.5, n.2, p.170-181, 2006

\begin{abstract}
RESUMO - O objetivo deste trabalho foi avaliar o comportamento da interceptação da radiação fotossinteticamente ativa (RFA) na cultura do milho, cultivado sob diferentes densidades populacionais, em espaçamento reduzido $(0,45 \mathrm{~m})$. Foi instalado um experimento para avaliar seis híbridos (A 2555, A 2288, AG 9010, AG 6690, P 30F88 e Valent), cultivados em cinco densidades (40 mil, 53 mil, 71 mil, 84 mil e 97 mil plantas por hectare), no município de Goiânia, estado de Goiás, na safra de verão 2002/2003. O delineamento experimental utilizado foi o de blocos ao acaso, com parcelas subdivididas, arranjadas em esquema fatorial 6x5, com quatro repetições. A interceptação da radiação fotossinteticamente ativa foi avaliada medindo-se a densidade do fluxo de fótons fotossinteticamente ativos: acima do dossel, na altura da espiga e ao nível do solo. Os resultados mostraram que existe correlação positiva entre a densidade de plantas e a interceptação da radiação. $\mathrm{O}$ adensamento proporcionado pelo incremento da densidade de semeadura em espaçamento reduzido permite uma maior interceptação da RFA, que tem como conseqüência um maior rendimento de grãos. Nas condições em que se avaliou a distribuição da radiação ao longo do dossel, pode-se concluir que o efeito da densidade sobre a maior interceptação da radiação disponível ocorre na parte superior do dossel, acima da altura das espigas.
\end{abstract}

Palavras-chave: dossel do milho, densidade de plantas, espaçamento entre linhas, atenuação da radiação solar

\section{INTERCEPTATION OF PHOTOSSINTETIC ACTIVE RADIATION AND GRAIN YIELD OF MAIZE UNDER HIGH PLANT DENSITY}

\begin{abstract}
The objective of this work was to evaluate the behavior of light attenuation (PAR) in maize hybrids, cultivated under different population densities in narrow row spacing $(0,45 \mathrm{~m}$ ). An experiment was installed to evaluate six hybrids (A 2555, A 2288, AG 9010, AG 6690, P 30F88 and Valent), cultivated in five plant densities (40, 53, 71, 84 and 97 thousand plants for hectare), in Goiânia, Goiás state, in the growing season $2002 / 2003$. The experimental design was randomized blocks with split plot, arranged in a $6 \times 5$ factorial with four replicates. The interceptation of photossintetic active radiation
\end{abstract}


was evaluated measuring photon flux density: above the canopy, in the height of the ear, and in soil surface. The results showed a positive correlation between grain yield and light attenuation. The increment on plant density in narrow row spacing resulted in a greater absorption of PAR, and consequently enhancements in grain yield. In these conditions, the results also showed that the light attenuation on maize canopy occurs in the superior part of the canopy, above the ear height.

Key words: Maize canopy, plant population, row spacing, light attenuation

O rendimento de grãos de uma comunidade pode ser incrementado maximizando sua eficiência fotossintética. Esta pode ser conseguida pela melhoria da interceptação da radiação fotossinteticamente ativa pelo dossel.

Do total de radiação que chega na superfície do dossel de uma cultura, parte é refletida, parte é absorvida e parte é transmitida, atingindo o solo com diferentes níveis energéticos, que variam conforme a estrutura do dossel (Norman \& Campbell, 1989). A atenuação da radiação em uma comunidade de plantas de milho depende da densidade de folhas, do arranjamento das folhas no dossel e da sua arquitetura, que determina a inclinação das folhas em relação à radiação solar incidente. Esses fatores, em conjunto, exercem grande influência no rendimento de grãos do milho (Ottman \& Welch, 1989; Maddonni et al., 2001).

Em geral, a interceptação da luz está relacionada ao índice de área foliar da cultura, por funções exponenciais (Hipps et al., 1983; Jones \& Kiniry, 1986). A eficiência fotossintética depende da taxa fotossintética por unidade de área foliar e da interceptação da radiação solar, as quais, entre outros aspectos, são influenciadas pelas características da arquitetura da copa e pela densidade de área foliar. Assim sendo, em condições de ausência de estresses bióticos ou abióticos, a superfície foliar (densidade de folhas) de uma planta é a base do rendimento potencial da cultura (Bonhomme et al., 1982; Gosse et al.,
1986; Muchow et al., 1990; Tollenaar \& Aguilera, 1992; Westgate et al., 1997), particularmente em regiões de curta estação de crescimento (Almeida \& Sangoi, 1996).

Pode-se potencializar o rendimento de grãos do milho por meio do aumento da quantidade de energia absorvida pelo dossel da comunidade, através do incremento da superfície foliar em uma determinada área de solo (Gallo et al., 1985; Ottman \& Welch, 1989). A escolha do arranjo de plantas adequado é uma das práticas de manejo mais importantes para otimizar o rendimento de grãos de milho, pois afeta diretamente a interceptação de radiação solar, que é um dos principais fatores determinantes da produtividade (Ottman \& Welch, 1989; Loomis \& Amthor, 1999). Além da redução do espaçamento entre linhas, outra forma de se melhorar a interceptação da radiação é através do aumento da densidade de plantas, proporcionada por cultivos adensados, com densidades acima de 60.000 plantas por hectare (Almeida \& Sangoi, 1996; Merotto Júnior et al., 1997; Almeida et al., 2000; Argenta et al., 2001; Sangoi et al., 2002; Marchão et al., 2005).

Para muitas culturas, pode-se calcular a interceptação da luz baseando-se na equação da Lei de Beer, sem ajustar o coeficiente de atenuação $k$ para os efeitos do arranjo das plantas no espaço, porém, para a cultura do milho, pode-se prever um aumento da interceptação da luz quando se decresce o espaçamento entre linhas e se aumenta a densidade de semeadura (Rosenthal 
et al., 1989), o que, na maioria dos casos, promove incrementos no rendimento de grãos (Karlen \& Camp, 1985). Este incremento resultante da utilização de menores espaçamentos e maiores densidades é conseqüência da melhor distribuição de plantas na área, que evita a excessiva competição, a qual somente ocorre quando a densidade de plantas é excessivamente alta ou quando há limitação de nutrientes e água (Mundstock, 1977).

Diversos trabalhos têm demonstrado que os híbridos de milho modernos não são cultivados sob baixas densidades (Duvick \& Cassmann, 1999; Sangoi et al., 2002a; Sangoi et al., 2002b; Tokatlidis \& Koutroubas, 2004), pois, além de produzirem somente uma espiga por planta, a melhoria no ambiente, representada por fatores como incremento na utilização de fertilizantes, desenvolvimento de novos herbicidas, adoção do sistema de plantio direto, além de outros fatores, tem favorecido cultivos adensados. De acordo com Flesch \& Vieira (1999), o melhoramento genético tem procurado obter plantas de milho com diferentes arquiteturas, de menor porte e folhas mais eretas, as quais tornariam possível uma semeadura mais densa, com conseqüente incremento no rendimento de grãos.

Dessa forma, o objetivo deste trabalho foi avaliar a influência do adensamento, proporcionada pelo aumento da densidade em espaçamento reduzido, sobre a interceptação da radiação fotossinteticamente ativa e seu conseqüente efeito sobre o rendimento de grãos do milho.

\section{Material e Métodos}

O experimento foi conduzido em Goiânia-GO, na área experimental da Escola de Agronomia e Engenharia de Alimentos, da Uni- versidade Federal de Goiás (latitude $16^{\circ} 35^{\prime} \mathrm{S}$, longitude $49^{\circ} 21^{\prime} \mathrm{W}$, altitude $727,00 \mathrm{~m}$ ), em Latossolo vermelho distrófico, de textura média, em relevo suave ondulado, sob sistema de plantio convencional. Adotou-se uma aração com grade pesada e um nivelamento com duas gradagens leves.

Foram avaliados seis híbridos comerciais, em cinco populações de plantas, cultivados em espaçamento de $0,45 \mathrm{~m}$ entre linhas. $\mathrm{O}$ delineamento experimental utilizado foi o de blocos completos casualizados, com os tratamentos arranjados em esquema fatorial $6 \times 5$, com quatro repetições. As densidades de semeadura planejadas foram 40.000, 55.000, 70.000, $85.000 \mathrm{e}$ 100.000 plantas por hectare, mas, devido ao ajuste pelo tamanho das parcelas, os valores observados foram 40.000, 53.333, 71.111, 84.444 e 97.777 plantas por hectare. Os híbridos utilizados no experimento foram: A 2555, A 2288, AG 9010, AG 6690, P 30F88 e Valent ${ }^{1}$, cujas características agronômicas estão descritas na Tabela 1 .

A semeadura ocorreu no dia 21 de novembro de 2002. A adubação de plantio foi feita conforme a análise química do solo, considerando-se uma expectativa de rendimento de grãos em torno de 6,0 $\mathrm{Mg} \mathrm{ha}^{-1}$, de acordo com a Comissão de Fertilidade de Solos-GO (1988). A semeadura foi feita manualmente, em sulcos preparados e adubados, a 5,0 $\mathrm{cm}$ de profundidade, utilizando-se uma semeadora de arraste em que as rodas compactadoras foram retiradas, para que os sulcos de semeadura permanecessem abertos. O desbaste foi efetuado aos vinte dias após a emergência (20 DAE) das plântulas.

O controle de plantas daninhas e insetospraga foi feito em duas etapas, sendo a primeira aplicação em pós-emergência inicial (15 DAE) e

\footnotetext{
${ }^{1}$ Os nomes dos produtos são incluídos em benefício dos leitores e não implicam recomendação ou preferência dos autores.
} 
TABELA 1. Características agronômicas dos híbridos de milho avaliados em diferentes densidades populacionais, em espaçamento reduzido, Goiânia, GO 2003.

\begin{tabular}{|c|c|c|c|c|c|c|c|c|}
\hline Cultivar & Empresa & Tipo $^{1}$ & Ciclo & $\begin{array}{l}\text { Época de } \\
\text { plantio }^{2}\end{array}$ & Cor do grão & $\begin{array}{c}\text { Altura da } \\
\text { planta } \\
(\mathrm{m})\end{array}$ & $\begin{array}{c}\text { Altura da } \\
\text { espiga } \\
\text { (m) }\end{array}$ & $\begin{array}{c}\text { Densidade } \\
\left(10^{3} \text { plantas } \mathrm{ha}^{-1}\right)\end{array}$ \\
\hline A 2555 & $\begin{array}{l}\text { Bayer } \\
\text { seeds }\end{array}$ & HS & $\begin{array}{c}\text { semi- } \\
\text { precoce }\end{array}$ & $\mathrm{V} / \mathrm{S}$ & avermelhado & 2,16 & 1,17 & 55 \\
\hline A 2288 & $\begin{array}{l}\text { Bayer } \\
\text { seeds }\end{array}$ & HS & precoce & $\mathrm{V} / \mathrm{S}$ & alaranjado & 2,14 & 1,04 & 60 \\
\hline AG 9010 & Monsanto & HS & $\begin{array}{l}\text { semi- } \\
\text { precoce }\end{array}$ & $\mathrm{V} / \mathrm{S}$ & alaranjado & 2,00 & 1,00 & $60-70$ \\
\hline AG 6690 & Monsanto & $\mathrm{HT}$ & precoce & $\mathrm{V}$ & alaranjado & 2,40 & 1,20 & $45-50$ \\
\hline P $30 F 88$ & Pioneer & HS & $\begin{array}{l}\text { semi- } \\
\text { precoce }\end{array}$ & V & alaranjado & $* *$ & $* *$ & $60-80$ \\
\hline Valent & Syngenta & HT & precoce & $\mathrm{V}$ & alaranjado & 2,43 & 1,21 & 55 \\
\hline
\end{tabular}

1- HS - híbrido simples, HT - híbrido triplo.

2- V - verão, S - safrinha.

** - sem informação

a Segunda, aos 30 DAE. Foram utilizados os inseticidas triflumuron $48 \%$, o lambdacyhalothrin 50 g. $\mathrm{L}^{-1}$, e o herbicida atrazine $500 \mathrm{~g} . \mathrm{L}^{-1}$ nas duas aplicações.

A unidade experimental constituiu-se de seis linhas de cinco metros, sendo considerada como área útil da parcela as quatro linhas centrais, desprezando-se as bordaduras.

A densidade de fótons fotossinteticamente ativos, em $\mu$ Einstein $\mathrm{s}^{-1} \mathrm{~m}^{-2}$, foi mensurada utilizando-se um monitor solar marca LI-COR, modelo LI 1776, e um sensor marca LI-COR, modelo LI 191SB Line Quantum. As leituras foram efetuadas quando cinquienta por cento dos hibridos atingiram o estádio de floração plena, nos dias 1e 2 de fevereiro de 2003, de forma contínua, entre as 11 e 14 horas. Os dias 1 e 2 de fevereiro apresentaram condições meteorológicas bastante semelhantes. Foram tomadas medidas em três pontos do dossel, sempre na região central da área útil das parcelas, de forma perpendicular às linhas de plantio. As medidas foram feitas acima do dossel das plantas, na altura de in- serção da primeira espiga e ao nível do solo, com o objetivo de estudar a atenuação da luz nas diferentes densidades de semeadura avaliadas. Depois de coletados, os dados foram transformados em percentual absorvido por camada, relativo ao total instantâneo incidente acima das parcelas. A radiação fotossinteticamente ativa (RFA) absorvida pela parte superior do dossel, até a altura da espiga (RFA-S) foi obtida subtraindo-se o percentual de energia absorvido até a mesma altura do total instantâneo incidente acima da parcela. Da mesma forma, calculou-se a RFA absorvida na parte inferior do dossel abaixo da espiga (RFA-I), e por fim, a RFA absorvida por todo o dossel (RFA-T).

Além da irradiância na faixa da RFA em cada parcela, também foram tomados os dados de alguns caracteres agronômicos que sofrem influência da densidade de plantas, entre eles o número de plantas acamadas e quebradas, a altura das plantas e a altura de inserção da $1^{a}$ espiga, medidas em cinco plantas dentro da área útil das parcelas. Por último, determinou-se o rendimen- 
to de grãos por parcela, em $\mathrm{Mg} \mathrm{ha}^{-1}$, corrigido para $13 \%$ em base úmida.

Os dados obtidos foram submetidos à análise de variância. Com o objetivo de estudar a relação entre a interceptação da RFA pelo dossel e os outros parâmetros avaliados, realizou-se uma análise de correlação simples (Correlação de Pearson), que foi apresentada quando houve correlação significativa. As médias dos dados correspondentes aos fatores quantitativos também foram submetidas à análise de regressão, pelo método dos quadrados mínimos ponderados, conforme Cruz \& Regazzi (1994). Os modelos para cada característica, em função da densidade de semeadura, foram apresentados quando o ajuste do modelo de regressão foi significativo.

\section{Resultados e Discussão}

Os resultados da análise de variância mostraram haver efeito significativo da densidade de plantas sobre a maioria dos parâmetros avaliados. Tanto o componente de rendimento (produtividade) quanto os caracteres agronômicos medidos (altura de inserção da primeira espiga, altura de planta, acamamento e quebramento) foram influenciados pela densidade de plantas (Tabela 2). Merotto Jr. et al., (1997a) encontraram resultado semelhante utilizando apenas um híbrido relativamente precoce e observaram que o aumento da densidade de semeadura provocou incremento na altura das plantas. Segundo os mesmos autores, esse incremento pode estar relacionado com a qualidade e a quantidade de luz que atravessa o dossel da cultura.

O estudo da atenuação da radiação fotossinteticamente ativa, em diferentes pontos do dossel do milho, mostrou que existe correlação positiva entre o rendimento de grãos e a interceptação da RFA-S e da RFA-T (Figuras 1 e 2). Esses resultados confirmam a hipótese de que o adensamento promovido pelo aumento da densidade de plantas em espaçamento reduzido aumenta a capacidade do dossel do milho em inter-

TABELA 2. Resumo das análises de variância, em quadrados médios (QM), coeficiente de variação (CV) e médias para altura de inserção da espiga (AE), altura da planta (AP), acamamento (AC), quebramento $(\mathrm{QB})$, interceptação da radiação fotossinteticamente ativa (RFA) na parte superior do dossel (RFA-S), interceptação na parte inferior do dossel (RFA-I), interceptação em todo o dossel (RFA-T) e rendimento de grãos (R) em Goiânia, GO, 2003

\begin{tabular}{|c|c|c|c|c|c|c|c|c|}
\hline $\begin{array}{l}\text { Fontes de } \\
\text { Variaçãa }{ }^{1}\end{array}$ & $\begin{array}{l}\mathbf{A E} \\
(\mathbf{m})\end{array}$ & $\begin{array}{l}\text { AP } \\
(\mathbf{m})\end{array}$ & $\begin{array}{l}\mathrm{AC} \\
(\%)\end{array}$ & $\begin{array}{l}\text { QB } \\
(\%)\end{array}$ & $\begin{array}{c}\text { RFA-S } \\
(\%)\end{array}$ & $\begin{array}{c}\text { RFA-I } \\
(\%)\end{array}$ & $\begin{array}{c}\text { RFA-T } \\
(\%)\end{array}$ & $\underset{\left(\mathrm{Mg} \mathrm{ha}^{-1}\right)}{\mathrm{R}}$ \\
\hline $\mathrm{H}$ & $* *$ & $* *$ & $* *$ & $* *$ & $\mathrm{~ns}$ & ns & $\mathrm{ns}$ & $* *$ \\
\hline $\mathrm{D}$ & $*$ & $*$ & $* *$ & $* *$ & $* *$ & ns & $* *$ & $* *$ \\
\hline $\mathrm{HxD}$ & ns & ns & $\mathrm{ns}$ & ns & ns & $\mathrm{ns}$ & ns & $*$ \\
\hline CV $(\%)$ & 7,15 & 4,66 & 123,67 & 214,66 & 15,87 & 41,93 & 9,97 & 7,70 \\
\hline Média & 1,07 & 2,12 & 4,65 & 1,65 & 70,59 & 59,95 & 88,05 & 8,54 \\
\hline
\end{tabular}

1 - H - Híbridos, D - Densidades, HxD - Interação híbridos x densidades

* - Valor significativo a 5\% de probabilidade, pelo teste $\mathrm{F}$.

** - Valores significativos a $1 \%$ de probabilidade. pelo teste $\mathrm{F}$. ns - Quadrado médio não significativo. 


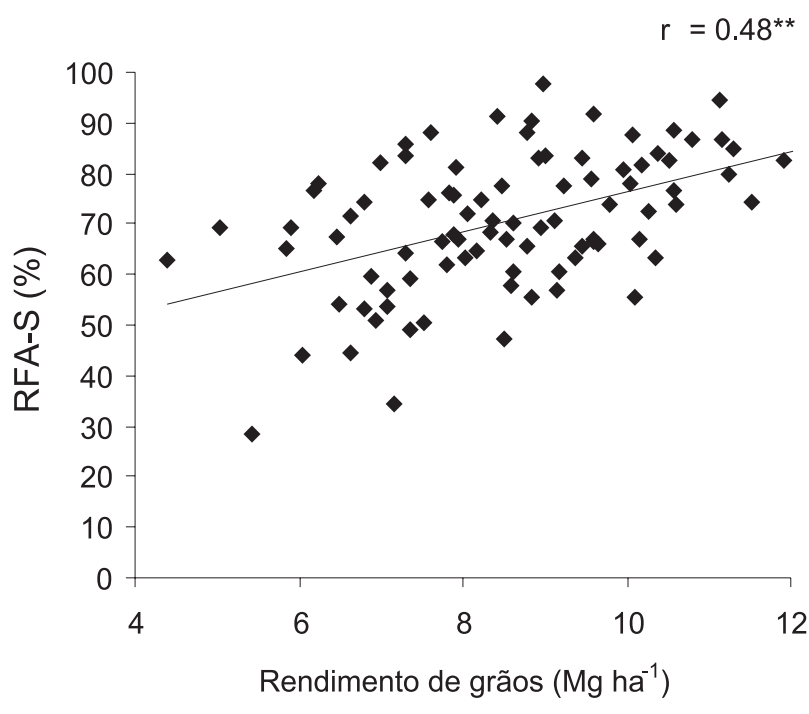

FIGURA 1. Correlação entre o percentual de interceptação da radiação fotossinteticamente ativa pela parte superior do dossel (RFA-S) e rendimento de grãos no milho. Dados de seis híbridos cultivados em cinco densidades de plantas e em espaçamento reduzido. Goiânia, GO. 2003.

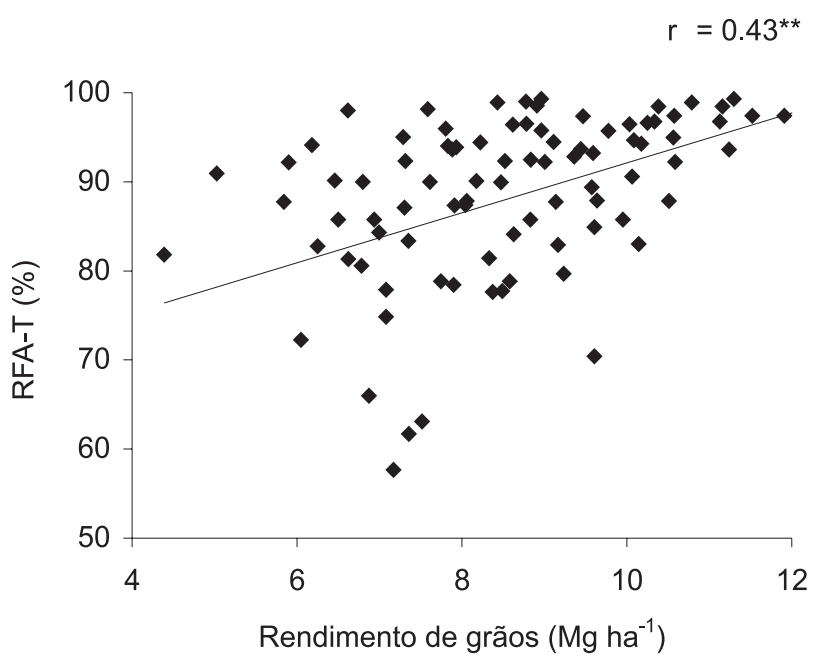

FIGURA 2. Correlação existente entre o percentual de interceptação da radiação fotossinteticamente ativa por todo o dossel (RFAT) e rendimento de grãos no milho. Dados de seis híbridos cultivados em cinco densidades de plantas e em espaçamento reduzido. Goiânia, GO 2003. ceptar melhor a radiação solar disponível em uma determinada área do solo. Diversos trabalhos relataram sobre a influência da arquitetura e do porte das plantas de milho sobre a interceptação da radiação solar disponível, em que híbridos simples, precoces e com folhas mais eretas sempre apresentam melhores resultados em experimentos com densidades de plantas. Neste trabalho, observou-se que somente houve efeito de híbridos quando foi medida a radiação interceptada até a altura das espigas, confirmando a hipótese de que a arquitetura e o porte das plantas são fatores determinantes da produtividade em cultivos adensados. Este resultado demonstra a importância de se utilizar híbridos com folhas mais eretas, sobretudo na parte superior das plantas, por serem mais eficientes na captação da luz que chega no dossel em condições de alta competição entre plantas.

A competição pela radiação solar incidente é um fator determinante do rendimento de grãos no milho, sobretudo em cultivo adensado, que pode resultar em um maior acúmulo de carbono pela comunidade e um acréscimo do número de grãos por espiga e também no peso do grão. Os resultados da análise de variância sobre o comportamento da radiação fotossinteticamente ativa, ao atingir o dossel do milho adensado, descritos na Tabela 2, mostram que a maior parte da interceptação ocorre na parte superior do dossel, acima da altura da espiga, pois não houve efeito significativo da densidade quando se mediu a radiação absorvida pela parte inferior do dossel ( $p>0,12$ e $p>0,08$ para densidades e híbridos, respectivamente). Só houve efeito da densidade sobre a RFA-S e a RFA-T. A Figura 3 mostra claramente, que quanto maior a altura das plantas, maior a interceptação da radiação pela parte superior do dossel. Esse resultado provavelmente pode estar relacionado com o maior crescimento da 
parte superior da planta, quando há um acréscimo da densidade de plantas (Figuras 5 e 6).

Com o objetivo de demonstrar o comportamento da interceptação da radiação fotossin-

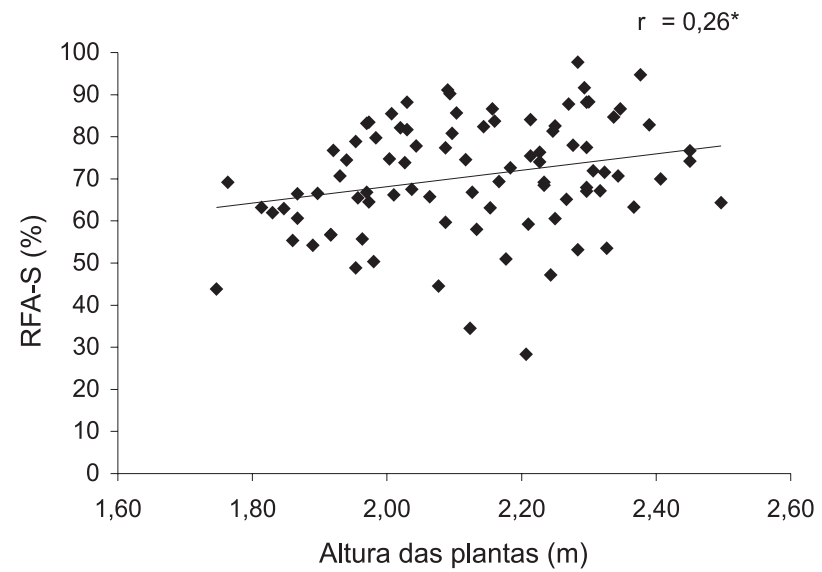

FIGURA 3. Correlação existente entre o percentual de interceptação da radiação fotossinteticamente ativa pela parte superior do dossel (RFA-S) e altura da planta. Dados de seis híbridos cultivados em cinco densidades de plantas e em espaçamento reduzido. Goiânia, GO. 2003.

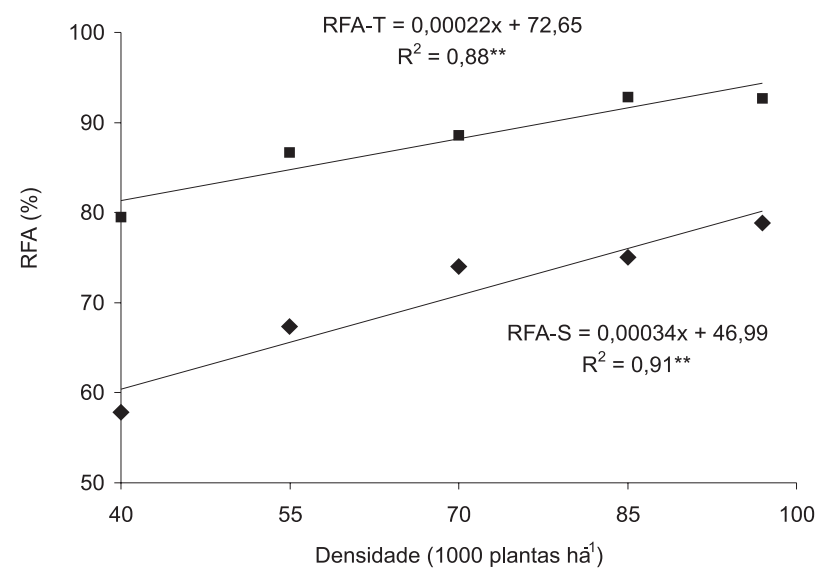

FIGURA 4. Interceptação relativa da radiação fotossinteticamente ativa até a altura da espiga (RFA-S) e por todo o dossel (RFA-T), em função da densidade de plantas em espaçamento reduzido. Médias de seis híbridos, Goiânia, GO. 2003. teticamente ativa pelo dossel, ajustaram-se modelos de regressão em função da densidade de plantas. Ao observar a Figura 4, nota-se que, tanto para interceptação da RFA-S, quanto para

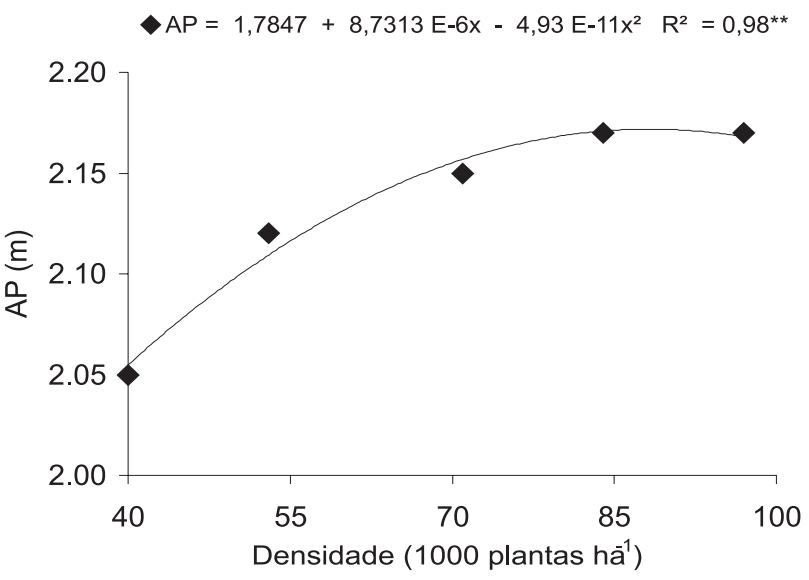

FIGURA 5. Altura de planta (AP) em função da densidade de plantas, em espaçamento reduzido. Médias de seis híbridos. Goiânia, GO. 2003.

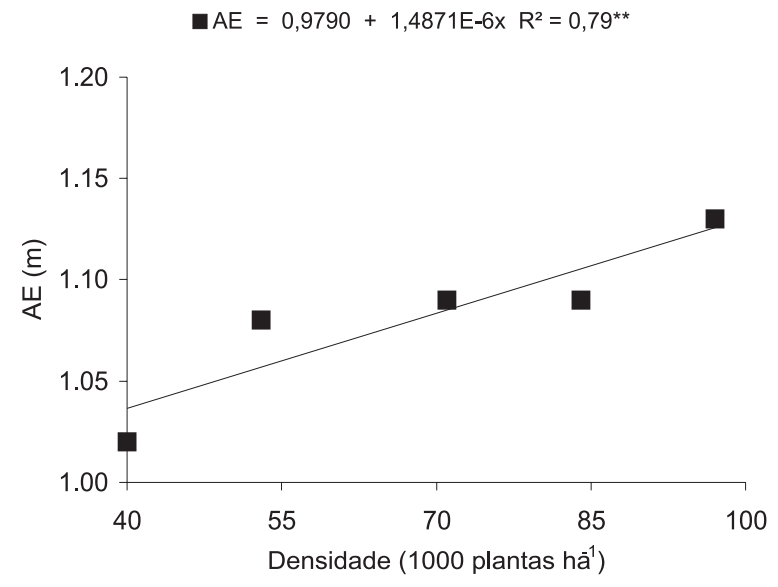

FIGURA 6. Altura de inserção da primeira espiga (AE) em função da densidade de plantas em espaçamento reduzido. Médias de seis híbridos. Goiânia, GO 2003. 
interceptação da RFA-T, houve um incremento linear com o aumento da densidade de plantas de 40 para próximo de 100 mil plantas por hectare.

O AG 9010, um híbrido simples, semiprecoce, e com arquitetura foliar ereta, foi o que alcançou as melhores médias de produtividade e apresentou comportamento linear de produtividade, demonstrando melhor adaptação à densidade acima de 85 mil plantas ha ${ }^{-1}$ que os demais híbridos analisados. Esse resultado corrobora diversos trabalhos que mostram que os híbridos simples são mais indicados ao cultivo adensado (Merotto Jr. et al., 1997a; Argenta et al., 2001a; Sangoi et al., 2002a; Dourado-Neto et al., 2003; Resende et al., 2003). Para o AG 9010, as características de porte baixo e folhas mais eretófilas podem ter sido fatores determinantes para o comportamento linear do rendimento de grãos. Outros trabalhos encontraram resultados semelhantes, em que os autores observaram que o uso de cultivares de menor porte é um fator determinante no cultivo adensado. Os acréscimos verificados no rendimento de grãos de cultivares com essas características possivelmente estão associados à maior capacidade de absorção da radiação solar no interior do dossel do milho, proporcionada pelo melhor arranjo das plantas no espaço (Tollenaar \& Aguilera, 1992).

Dentre os componentes de produção, destaca-se o rendimento de grãos, que apresentou incremento significativo com o adensamento ocasionado pelo aumento da densidade em espaçamento reduzido (Figura 7). Este foi o único parâmetro avaliado em que os híbridos apresentaram comportamento diferencial em relação às densidades de plantas, como mostra a Tabela 2, onde há efeito da interação de híbridos e densidades de plantas $(\mathrm{p}<0,05)$. Os acréscimos verificados no rendimento de grãos das cultivares

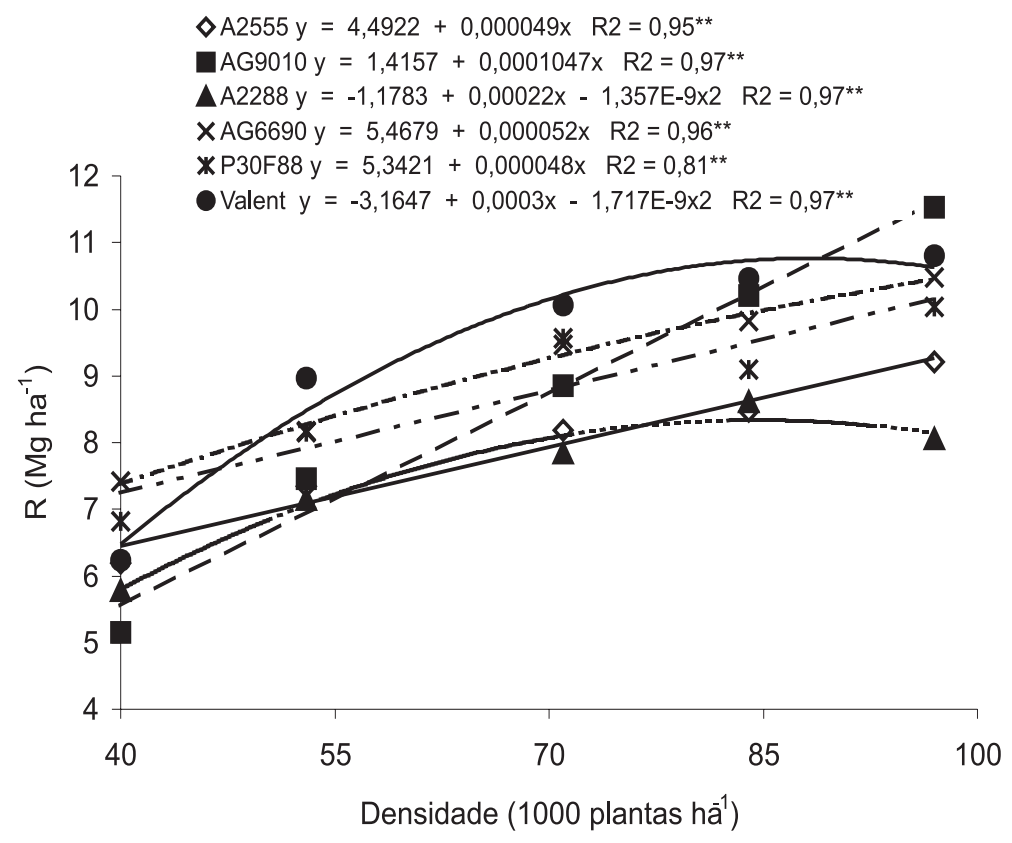

FIGURA 7. Rendimento de grãos (R) em função da densidade de plantas em espaçamento reduzido, Goiânia, GO. 2003. 
avaliadas nessas condições, possivelmente, estão associados à maior capacidade de interceptação da radiação solar no interior do dossel do milho. Essa maior interceptação, proporcionada pelo melhor arranjo das plantas no espaço e, conseqüentemente pelo maior aproveitamento da radiação disponível, é fator determinante para o rendimento de grãos do milho (Tollenaar \& Aguilera, 1992). Na Figura 4, estão os modelos das regressões que mostram o comportamento linear da interceptação da radiação até a altura da espiga (RFA-S), e em todo o dossel do milho (RFA-T), ajustadas em função da densidade de plantas. Esses resultados corroboram diversos trabalhos (Merotto Jr. et al., 1997a; Maddonni et al., 2001; Sangoi et al., 2002b) que demonstraram haver alta sensibilidade da estrutura do dossel do milho ao arranjo espacial das plantas, e que esse efeito depende da arquitetura foliar e da estrutura do dossel como um todo. $\mathrm{O}$ efeito do adensamento se expressa sobre as plantas, havendo ocorrência de dominância apical em condições de altas densidades populacionais e maior crescimento em altura devido à competição por luz, tendo como consequiência diversas alterações morfofisiológicas (Sangoi et al., 2002b).

Os resultados da análise de variância mostraram haver efeito significativo da densidade de plantas sobre o número final de plantas acamadas e quebradas dentro do dossel, porém, observa-se que os valores médios, tanto de acamamento, quanto de quebramento, não são tão elevados (Tabela 2), permitindo concluir que esses fatores não foram limitantes ao cultivo adensado, nas condições em que se conduziu o experimento. Todavia, deve-se considerar que em experimentos com densidades de plantas variável, esses caracteres apresentam, normalmente, altos coeficientes de variação. Outro ponto a ser considerado é que, dentre as plantas acamadas e quebradas, a maior parte apresentou sintomas de ataque da broca do colmo (Diatraea saccharalis), que danifica o colmo, aumentando a susceptibilidade da planta ao tombamento.

De maneira geral, todas as cultivares avaliadas apresentaram incremento significativo do rendimento de grãos quando cultivadas em densidades acima das tradicionalmente utilizadas, devendo sempre ser observado o efeito do cultivo em espaçamento reduzido, que proporcionou uma melhor distribuição das plantas no espaço. Neste experimento, o híbrido A 2288 foi o que menos se mostrou apto para cultivos em densidades muito elevadas, seu comportamento quadrático demonstra que pode ter havido influência do efeito de local. Tradicionalmente, na região dos Cerrados, o melhoramento genético prima por selecionar híbridos para regiões de chapada, com altitudes acima de $900 \mathrm{~m}$ e temperaturas mais amenas durante a noite, o que não é o caso do local aqui estudado. O híbrido A 2288 e o Valent, um híbrido triplo, foram os únicos que apresentaram comportamento quadrático de resposta do rendimento ao adensamento. As demais cultivares, apesar de apresentarem menores médias que o AG 9010, também apresentaram comportamento linear em relação ao adensamento.

Diversos trabalhos têm demonstrado que híbridos de ciclo precoce e porte baixo têm conseguido alcançar altos níveis de produtividade quando cultivados em espaçamento reduzido e com altas densidades de plantas (Merotto Jr. et al., 1997a; Merotto Jr. et al., 1997b; Flesch \& Vieira, 1999; Almeida et al., 2000; Sangoi et al., 2002). Esses resultados corroboram as afirmações de Tollenar \& Wu (1991) e Sinclair (1998), de que os genótipos de milho de menor porte, menor número de folhas e de folhas eretófilas 
apresentam maior capacidade de acumulação de matéria seca na comunidade, sem, com isso, reduzirem drasticamente a emissão e a manutenção das espigas pelas plantas. Sangoi et al. (2002) verificaram que mudanças na população de plantas induziram altas variações no número de grãos por espiga e do peso dos grãos, confirmando os resultados aqui encontrados.

\section{Conclusões}

$\mathrm{O}$ adensamento proporcionado pelo incremento da densidade de semeadura em espaçamento reduzido é uma prática de manejo que permite um maior rendimento de grãos em decorrência do aumento linear da interceptação da luz pelo dossel.

Nas condições em que se avaliou a atenuação da radiação ao longo do dossel, observou-se um comportamento diferencial da interceptação da radiação em função da densidade de semeadura utilizada, em espaçamento reduzido entre linhas.

\section{Agradecimento}

Ao professor Dr. Engler José Vidigal Lobato da Escola de Agronomia da UFG, e ao Dr. Cleber Morais Guimarães da Embrapa Arroz e Feijão pelas sugestões e correções deste trabalho.

\section{Literatura Citada}

ALMEIDA, M. L. ; SANGOI, L. Aumento da densidade de plantas de milho para regiões de curta estação estival de crescimento. Pesquisa Agropecuária Gaúcha, Porto Alegre, v. 2, n. 2, p. 179-183, 1996.

ALMEIDA, M. L.; MEROTTO JUNIOR, A.; SANGOI, L.; ENDER, M.; GUIDOLIN, A. F. Incremento na densidade de plantas: uma alternativa para aumentar o rendimento de grãos de milho em regiões de curta estação estival de crescimento. Ciência Rural, Santa Maria, v. 30, n. 1, p. 23-29, 2000.

ARGENTA, G.; SIVA, P. R. F.; BORTOLINI, C. G.; FORSTHOFER, E. L.; MANJABOSCO, E. A.; BEHEREGARAY NETO, V. Resposta de híbridos simples de milho à redução do espaçamento entre linhas. Pesquisa Agropecuária Brasileira, Brasília, DF, v. 36, n. 1, p. 71-78, 2001a.

BONHOMME R.; RUGET F.; DERIEUX M.; VINCOURT. P. Relationship between aerial dry matter production and intercepted solar radiation for various maize genotypes. Comptes Rendus Hebdomaires des Seances Academie Science Ser. III, Paris v. 294, p. 393-398, 1982.

COMISSÃO DE FERTILIDADE DE SOLOS DE GOIÁS. Recomendações de corretivos e fertilizantes para Goiás: 5a aproximação. Goiânia: UFV/EMGOPA, 1988. 101p. (Informativo Técnico, 1).

CRUZ, C. D.; REGAZZI, A. J. Modelos biométricos aplicados ao melhoramento genético. Viçosa: UFV, 1994. 390 p.

DOURADO-NETO, D.; PALHARES, M.; VIEIRA, P. A.; MANFRON, P. A.; MEDEIROS, S. L. P.; ROMANO, M. R. Efeito da população de plantas e do espaçamento sobre a produtividade de milho. Revista Brasileira de Milho e Sorgo, Sete Lagoas, v. 2, n. 3, p. 63-77, 2003.

DUVICK, D. N.; CASSMAN, K. G. Post-green revolution trends in yield potential of temperate maize in the North-Central United States. Crop Science, Madison, v. 39, p. 1622-1630, 1999.

FLÉNET, F.; KINIRY, J. R.; BOARD, J. E.; WESTGATE, M. E.; REICOSKY, D. C. Row 
spacing effects on light extinction coefficients of corn, sorghum, soybean, and sunflower. Agronomy Journal, Madison, v. 88, n. 2, p. 185190, 1996.

FLESCH, R. D.; VIEIRA, L. C. Espaçamento e população de plantas na cultura do milho. Agropecuária Catarinense, Florianópolis, v. 12, n. 2, p. 28-31, 1999.

HIPPS, L. E.; ASRAR, G.; KANEMASU, E. T. Assesing the intercepcion of photosynthetically active radiation in whinter wheat. Agricultural Meteorology, Amsterdan, v. 28, p. 253-259, 1983.

GALLO, K. P.; DAUGHTRY, C. S. T.; BAUER, M. E. Spectral estimates of absorbed photosynthetically active radiation in corn canopies. Remote Sensing Environment, New York, v. 17, p. 221-232, 1985.

GOSSE, G.; VARLET-GRANCHER C.; BONHOMME R.; CHARTIER M.; ALLIRAND A.; LEMAIRE G. Maximum dry matter production and solar radiation intercepted by a canopy. Agronomie, Paris, v. 6, p. 47-56, 1986.

JONES, C.; KINIRY, J. Ceres-N Maize: a simulation model of maize growth and development. Texas: A \& M University Press, 1986.

KARLEN, D. L.; CAMP, C. R. Row spacing, plant population, and water management effects on corn in the Atlantic coastal plain. Agronomy Journal, Madison, v. 77, n. 3, p. 393-398, 1985.

LI-COR. LI-1776 plant canopy analyzer: instruction manual. Lincoln, 1992. 182 p.

LOOMIS, R. S.; AMTHOR, J. S. Yield potential, plant assimilatory capacity, and metabolic efficiencies, Crop Science, Madison, v. 39, p. 1584-1596, 1999.
MADDONNI, G. A.; OTEGUI, M. E.; CIRILO, A. G. Plant population density, row spacing and hybrid effects on maize canopy architecture and light attenuation. Field Crops Research, Amsterdan, v. 71, n.1, p. 183-193, 2001.

MARCHÃO, R. L. BRASIL, E. M.; DUARTE, J. B.; GUIMARÃES, C. M.; GOMES, J. A. Densidade de plantas e características agronômicas de híbridos de milho em espaçamento reduzido entre linhas. Pesquisa Agropecuária Tropical, Goiânia, v. 35 n. 2, p. 93-101, 2005.

MEROTTO JUNIOR, A.; ALMEIDA, M. L.; FUCHS, O. Aumento do rendimento de grãos de milho através do aumento da população de plantas. Ciência Rural, Santa Maria, v. 17, n. 4, p. 549- 554, 1997.

MUNDSTOCK, C. M. Milho: distribuição da distância entre linhas. Lavoura Arrozeira, Porto Alegre, n. 299, p. 28-29, 1977.

MUCHOW, R. C.; SINCLAIR, T. R.; BENNETT, J. M. Temperature and solar radiation effects on potential maize yield across locations. Agronomy Journal, Madison, v. 82, p. 338-343, 1990.

NORMAN, J. M.; CAMPBELL, G. S. Canopy structure. In: PEARCY, R. W.; HLERINGER, J.; MOONEY, H. A.; RUNDEL, P. W. (Eds.). Plant physiological ecology: field methods and instrumentation. London: Chapman and Hall, 1989. p. 301-326.

OTTMAN, M. J.; WELCH, L. F. Planting patterns and radiation interception, plant nutrient concentration, and yield in corn. Agronomy Journal, Madison, v. 81, n. 2, p. 167-174, 1989.

RESENDE, S. G. de; PINHO, R. G. von; VASCONCELOS, R. C. de. Influência do 
espaçamento entre linhas e da densidade de plantio no desempenho de cultivares de milho. Revista Brasileira de Milho e Sorgo, Sete Lagoas, v. 2, n. 3, p. 34-42, 2003.

ROSENTHAL, W. D. ; VANDERLIP, R. L.; JACKSON, B. S.; ARKIN, G. F. SORKAM: a grain sorghum crop growth model. College Station: Texas Agricultural Experimental Station., 1989. (Rep. MP-1699).

SANGOI, L.; GRACIETTI, M. A.; RAMPAZZO, C.; BIANCHET, P. Response of Brazilian maize hybrids from different eras to changes in plant density. Field Crops Research, Amsterdan, v.79, p.39-51, 2002a.

SANGOI, L. ALMEIDA, M. L. de; SILVA, P. R. F. da; ARGENTA, G. Bases morfofisiológicas para maior tolerância dos híbridos modernos de milho a altas densidades de plantas. Bragantia, Campinas, v. 61, n. 2, p. 101-110, 2002b.

TOKATLIDIS, I. S.; KOUTROUBAS, S. D. A review of maize hybrids dependence on high plant populations and its implications for crop yield stability. Field Crops Research, Amsterdan, v. 88, p. 103-114, 2004.

TOLLENAAR, M.; AGUILERA, A. Radiation use efficiency of an old and a new maize hybrid. Agronomy Journal, Madison, v. 84, n. 3, p. 536541, 1992.

WESTGATE, M. E., FORCELLA, F., REICOSKY, D. D., SOMSEN, J. Rapid canopy closure for maize production in the northern US corn belt: Radiation-use efficiency and grain yield. Field Crops Research, Amsterdan, v.49, n.2, p. 249258, 1997. 